\title{
Arquitetura x autismo: desafios da inclusão em centros equoterápicos
}

\author{
Architecture $\mathbf{x}$ autism: challenges of inclusion in equestrian centers \\ Arquitectura $x$ autismo: retos de la inclusión en los centros ecuestres
}

Recebido: 14/10/2021 | Revisado: 21/10/2021 | Aceito: 23/10/2021 | Publicado: 25/10/2021

\author{
Ana Karolina Santana Santos \\ ORCID: https://orcid.org/0000-0002-1531-8121 \\ Faculdades Santo Agostinho, Brasil \\ E-mail: karolina.uesb25@gmail.com \\ Priscilla Sandes Ferraz \\ ORCID https://orcid.org/0000-0002-7559-5518 \\ Faculdades Santo Agostinho, Brasil \\ E-mail: sandes.priscilla@gmail.com
}

\begin{abstract}
Resumo
Atualmente, a diversidade de formas de tratamento terapêutico para crianças autistas proporciona possibilidades variadas de recursos. Nesse sentido, a terapia com cavalos, é destaque como ferramenta dentro de uma abordagem complementar e interdisciplinar. Estudos sobre a equoterapia apontam o aporte para autonomia e motricidade, para ser considerada efetiva o espaço físico precisa contar com elementos arquitetônicos com o propósito de assegurar a inclusão. O objetivo deste artigo é discutir os desafios da arquitetura inclusiva em centros de equoterapias. Para tanto a metodologia empregada se baseia em uma pesquisa exploratória bibliográfica aplicada prática e estudo de caso, com intenção de identificar problemas e fazer levantamento de dados sobre estruturas físicas de centros equoterápicos em Vitoria da Conquista situado no estado da Bahia. Ao final, os resultados apontaram a existência de legislação que garante a inclusão, no entanto, percebe a necessidade de pensar e muitas vezes adequar os espaços físicos dos centros terapêuticos, a fim de viabilizar às crianças autistas o direito de usufruir de ambientes inclusivos. Assim, conclui-se que a arquitetura inclusiva é o caminho possível para assegurar aos autistas a melhor forma de auxílio no enfrentamento dos obstáculos vivenciados como também incumbir acolhimento e acessibilidade em centros equoterápicos.
\end{abstract}

Palavras-chave: Arquitetura inclusiva; Autismo; Equoterapia.

\begin{abstract}
Currently, the diversity of forms of therapeutic treatment for autistic children provides various possibilities of resources. In this sense, horse therapy is highlighted as a tool within a complementary and interdisciplinary approach. Studies on horse therapy point out the contribution to autonomy and motor skills, to be considered effective the physical space needs to have architectural elements with the purpose of ensuring inclusion. The objective of this article is to discuss the challenges of inclusive architecture in equotherapy centers. To this end, the methodology used is based on an exploratory bibliographic research applied to practical and case study, with the intention of identifying problems and collecting data on physical structures of horse-riding centers in Vitoria da Conquista situated in the state of Bahia. In the end, the results pointed out the existence of legislation that guarantees inclusion, however, perceives the need to think and often adapt the physical spaces of therapeutic centers, in order to enable autistic children the right to enjoy inclusive environments. Thus, it is concluded that inclusive architecture is the possible way to ensure autistic children the best way to help them face the obstacles they experience, as well as to provide hospitality and accessibility in equine therapy centers.
\end{abstract}

Keywords: Inclusive architecture; Autism; Equotherapy.

\section{Resumen}

En la actualidad, la diversidad de formas de tratamiento terapéutico para los niños autistas ofrece varias posibilidades de recursos. En este sentido, la terapia con caballos se destaca como una herramienta dentro de un enfoque complementario e interdisciplinario. Los estudios sobre la terapia con caballos señalan la contribución a la autonomía y a las habilidades motoras, para ser considerada efectiva el espacio físico necesita tener elementos arquitectónicos con el propósito de garantizar la inclusión. El objetivo de este artículo es debatir los retos de la arquitectura inclusiva en los centros de terapia ecuestre. Por lo tanto, la metodología utilizada se basa en una investigación bibliográfica exploratoria aplicada a la práctica y al estudio de casos, con la intención de identificar los problemas y los datos de la encuesta sobre las estructuras físicas de los centros hípicos de Vitoria da Conquista situados en el estado de Bahía. Al final, los resultados señalaron la existencia de una legislación que garantiza la inclusión, sin embargo, se percibe la necesidad de pensar y muchas veces adaptar los espacios físicos de los centros terapéuticos, con el fin de hacer posible a los niños autistas el derecho a disfrutar de entornos inclusivos. Así, se concluye que la arquitectura inclusiva 
es la forma posible de asegurar a los autistas la mejor manera de ayudarles a afrontar los obstáculos que experimentan, así como de proporcionarles refugio y accesibilidad en los centros de equinoterapia.

Palabras clave: Arquitectura inclusiva; Autismo; Equinoterapia.

\section{Introdução}

A arquitetura inclusiva se caracteriza pelos aspectos abrangentes para as necessidades diversas de pessoas dentro de um plano arquitetônico regido por normas e técnicas, contudo, sendo possível dizer também que um projeto de edificação vai muito além de seguir um conjunto de regras de acessibilidade, segundo Russo (2017) a arquitetura pode ser percebida como ciência exata quando se dedica em projetar, mas por outro lado mostra-se como ciência humana por atender as necessidades incontáveis e subjetivas do ser humano.

Dentro dessa perspectiva, o trabalho introduz um breve estudo sobre uma face dessa inclusão, a respeito das necessidades de crianças com Transtorno Espectro Autista (TEA). Os transtornos globais do desenvolvimento (TGD), conhecido por "espectro autista", formam um conjunto de síndromes definidas por alterações no comportamento (Maciel, 2009). O autismo revela-se complexo para o diagnóstico, devendo ser investigados por uma equipe técnica de profissionais, para compreender as dinâmicas e demandas de uma criança autista. Dentro dessa perspectiva, vale destacar os profissionais envolvidos no desenvolvimento dos espaços físicos, em especial os arquitetos e urbanista, pois para projetar espaços destinados para indivíduos com esse transtorno, o profissional de arquitetura precisa refletir sobre sua atuação, e compreender as particularidades de cada indivíduo, aprofundando o olhar, para então entender que cada indivíduo percebe o mundo de maneira própria e particular, para Maciel (2009) seu aparente alheamento disfarça o fato de, em geral, estarem presentes e serem extremamente sensíveis, mas com dificuldades para se comunicar.

Partindo desses princípios de inclusão, a relevância de tratamentos adequados para promover qualidade de vida a crianças autistas, engloba também a Terapia Assistida por Animais (TAA), conhecida como Equoterapia. Segundo Eckert (2013) pode ser descrita como um recurso terapêutico relacionado à reabilitação, diferenciando-se do tratamento clínico convencional por ser realizada ao ar livre, gerando um vínculo afetivo, tanto em crianças com transtorno do espectro autista, quanto para outros indivíduos com ou sem necessidade terapêutica. De acordo com a Secretaria Geral da União, regulamentada pela Lei 13.830 (13-05-2019) a equoterapia como método de reabilitação de pessoas com deficiência deve ser realizado por uma equipe multifuncional de médicos, médicos veterinários, psicólogos, fisioterapeutas, pedagogos e equitadores. Segundo Medeiros (2002), o histórico da utilização do cavalo na área de saúde é tão antigo quanto a própria história da medicina, pois a equoterapia faz uso das tarefas equestres na intenção de promover em seus praticantes benefícios físicos, psicológicos, educacionais e sociais (Silveira \& Wibelinger, 2011).

De acordo com os dados da Associação Nacional de Equoterapia (Ande-Brasil, 2016) existem no estado da Bahia 11 centros de equoterapia sendo 2 no município de Vitoria da Conquista. O Centro Conquista de Equoterapia, funciona no parque de exposições, sendo um espaço adaptado a equoterapia e atua como local para outras atividades dentro do município, revelando um desconforto para quem precisa dessa terapia, o uso do ambiente depende de variáveis e não necessariamente dizem respeito as exiguidades dos usuários. O Centro de Equoterapia e Instituto Lar dos Kerubins, apesar de ser um instituto voltado apenas para a equoterapia e possuir o tripé da TAA, saúde, educação e equitação (Ande-Brasil, 2016), não dispõe de instalações físicas suficientes para acolher de forma integral as condições aplicadas as crianças com TEA, sendo carente de um projeto arquitetônico para viabilizar a acessibilidade e o conforto da realização de atividades equestres com fins terapêuticos.

Para Ribeiro (2014), no município de Vitória da Conquista na Bahia, 51\% das crianças com necessidades especiais são indicadas por profissionais da área para o tratamento de terapia assistida por animais, e destes, $86 \%$ tiveram resultados muito satisfatórios. A pesquisa também ressalta a porcentagem referente as crianças que não tiveram resultados com a terapia e não se mostraram frequentes nas atividades. Ainda nesta investigação, os benefícios observados foram equilíbrio, respiração, 
controle corporal, comportamento, controle de saliva, equilíbrio cervical, fala, entendimento e mastigação (Ribeiro, 2014). Diante dessa observação, a discussão sobre adequação de centros de equoterapia para o município, justifica-se por entender que Vitória da Conquista é reconhecida como um polo de saúde, serviço e educação para a região sudoeste do estado (IBGE, 2021) e, portanto, a relevância da terapia para crianças autistas faz-se essencial para toda comunidade circunvizinha.

Neste cenário, tendo como objetivo discutir os desafios da arquitetura inclusiva em centro equoterápico, o presente trabalho visa apresentar breve estudo sobre a relevância da equoterapia em crianças com TEA e apontar de que maneira a arquitetura se faz relevante para ambientes destinados a TAA em razão de crianças autistas. Além desta introdução, o artigo apresenta a metodologia de pesquisa utilizada e referencial teórico em um tópico subdividido em três subtópicos, a saber: Arquitetura Inclusiva, A criança Autista, O Autista e o Direito a Arquitetura Inclusiva e A Equoterapia, em seguida, os resultados e discussão e as considerações finais com os principais achados do estudo.

\section{Metodologia}

O presente trabalho, descreve como proposta metodológica abordado por Lakatos e Marconi (2003, p.83) como "o método é o conjunto das atividades sistemáticas e racionais que, com maior segurança e economia, permite alcançar o objetivo - conhecimentos válidos e verdadeiros." De modo a discutir baseado em estudos sobre como arquitetura acrescenta a perspectiva da inclusão em espaços terapêuticos.

Para estruturar uma pesquisa científica torna-se indispensável reunir informações, a serem utilizadas nas etapas de designação da proposta, considerando que se trata de uma pesquisa aplicada prática e estudo de caso, constatando uma problemática pertinente ao estudo em questão a ser solucionada (Gil, 2010). Visto que "parte de um problema, ao qual se oferecesse uma espécie de solução provisória, passando-se depois a criticar a solução, com vista à eliminação do erro." (Lakatos \& Marconi, 2003, p. 95), com procedimentos que visam à coleta de informações.

Faz-se necessidade antepor como opção metodológica a pesquisa bibliográfica, para Oliveira (2007), um estudo direto em fontes científicas, sem precisar recorrer à realidade empírica, auxiliando na fundamentação teórica da investigação, por meio de artigos científicos, livros, documentos monográficos e dissertações, tendo como principais teóricos Maria M. Maciel (2009), Michele M. da Silveira (2011), Katiuscia C. Vargas Antunes (2007), Temple Grandin (2014), Gilles Deleuze (2009). Por conseguinte, utiliza-se uma análise documental dos dados divulgados pelo Associação Nacional de Equoterapia (ANDEBrasil), Secretaria Geral da República, Estatuto da Pessoa com Deficiência, além da avaliação de dados e informações do município Vitoria da Conquista, Bahia, bem como NBR 9050, referente a normas de acessibilidade e o estudo de campo, por meio da observação e demonstração de fotos. Logo, o estudo aborda sobre a arquitetura inclusiva para em seguida conceituar as relações de direito da criança autista em um ambiente que trate da inclusão de maneira abrangente dentro da arquitetura, discorrendo sobre quais os problemas identificados na estrutura física de centro de equoterapia, suas influências e a aplicabilidade da acessibilidade e estímulos sensoriais.

\section{Resultados}

\subsection{Arquitetura Inclusiva}

A história da humanidade marcada por evolução e desenvolvimento como um todo, revela seres dotados de capacidade de reflexão e por isso com possibilidade de aprender, trocando vivencias e informações. Essas trocas são essenciais para a percepção de mundo e a arquitetura pode ser encarada como ferramenta para atender necessidades da pluralidade de pessoas, suas exiguidades exigem para essas comutações a base da evolução da sociedade (Rodrigues \& Vergara, 2019). Dentro dessa reflexão faz-se oportuno pensar em inclusão quando incluir é fazer a junção de suas histórias e capacidades entre indivíduos. 
A palavra inclusão apresenta diversos sinônimos segundo Bechara (2009), entre eles integração, inserção, junção e incorporação, sendo esses os satisfatórios para exprimir o significado do papel da arquitetura inclusiva nessa perspectiva. Entretanto, Vergara (2011) aponta que a inclusão não é amplamente assegurada na sociedade, o processo de exclusão pode ocorrer em áreas como, políticas públicas, institucionais, culturais, sociais e até mesmo em ambiente familiar, isso ocorre por meio de atitudes, ações e até palavras ocasionam um desligamento, uma desincorporação e uma desintegração dos seus direitos individuais e coletivos (Vergara et al, 2011). Como garantia para acessibilidade pode-se observar que

A lei brasileira, $\mathrm{n}^{\circ}$ 13.146, de 6 de julho de 2015, trata da inclusão da pessoa com deficiência e seus direitos fundamentais, declarando: Art. $4^{\circ}$ - Toda pessoa com deficiência tem direito à igualdade de oportunidades com as demais pessoas e não sofrerá nenhuma espécie de discriminação.§ $1^{\circ}$ Considera-se discriminação em razão da deficiência toda forma de distinção, restrição ou exclusão, por ação ou omissão, que tenha o propósito ou o efeito de prejudicar, impedir ou anular o reconhecimento ou o exercício dos direitos e das liberdades fundamentais de pessoa com deficiência, incluindo a recusa de adaptações razoáveis e de fornecimento de tecnologias assistivas (BRASIL, 2015, Art. $\left.4^{\circ}, \S 1^{\circ}\right)$.

O papel da arquitetura inclusiva está em contribuir com o processo de reinclusão, para Deleuze (2009), a inclusão deve ser encarada a partir da diversidade de todos, seres singulares, onde a diferença é aceita e respeitada e o projeto arquitetônico materializa nos espaços os direitos a lei n¹3.146. Dentro do planejamento e idealização de ambientes, torna-se imprescindível entender que as pessoas têm condições e necessidades diferentes ao longo da vida. Para a pesquisadora Martins et al (2017) "a arquitetura inclusiva parte do conceito de inclusão social" de um caráter coletivo, dedicando-se ao amparo em espaços físicos a pessoas com deficiência, ampliando os benefícios assegurados a pessoa com necessidades diversas, para autonomia tanto em tarefas do cotidiano quanto na locomoção (Martins et al, 2017, p.15). As edificações, em grande maioria, não foram pensadas para estimular a inclusão e principalmente o desenvolvimento de crianças com transtorno do espectro autista, tendo assim uma crítica a arquitetura sem pensar na inclusão, (Antunes, 2017).

\subsection{A Criança Autista}

O Transtorno do Espectro Autista (TEA), nomenclatura utilizada para se referir ao transtorno do desenvolvimento que leva ao comprometimento na comunicação e interação social, englobando comportamentos restritivos e repetitivos (Grandin, 2014). Segundo a pesquisadora Maciel (2009), apesar de muitas dissertações e pesquisar a respeito ainda não se pode dizer as causas para o autismo, ao destacar que:

Não há consenso, na comunidade científica, sobre as causas do autismo. Pode apresentar de formas suaves a graus severos de comprometimento, podendo vir associado a outras síndromes, como Down, Williams, X-Frágil, afetando ainda mais a pessoa, mas muitos têm inteligência média, podendo mesmo ser bastante inteligentes (Maciel, 2009, p.1).

Assim, a palavra autismo, segundo Grandin (2014), em seu livro: "O cérebro autista" formado por auto (do gr. referente a si mesmo) ismo (sufixo indica ação ou estado), essa termologia reitera a percepção da escassa interação dos indivíduos com espectro autista com outros indivíduos, a dificuldade de compreender as reações e interações de uma outra pessoa. Essa falta de inter-relação se dá em não se sentir seguro com novos indivíduos e assim, preferem a segurança de ambientes e pessoas conhecidas com familiaridade (Grandin, 2014).

Segundo Amorim (2020) o diagnóstico do TEA baseia-se, atualmente, em análises do comportamento feito por profissionais especializados, apesar de não se basear em exames clínicos para o diagnóstico não se trata de uma investigação subjetiva do caso. Para Maciel (2009) as normas norte-americanas (DSM-IV), indicam o reconhecimento por meio de seis ou mais sinais a seguir em uma criança ou até mesmo em adultos, com ao menos dois do grupo 1, e um do grupo 2 e um do grupo 
3. Essa consideração também conhecida como "tríade autista": Socialização, Comunicação, Comportamento. De acordo com a pesquisadora Maciel (2009) as características de cada grupo são:

- Dano na interação social: a) carência na comunicação e expressões faciais e também corporais; b) falta de interatividade social em fazer novas amizades; c) ruína em compartilhar emoções pessoais; d) ausência de reciprocidade (não percebe os sentimentos alheios).

- Dano na comunicação: a) atraso ou falta de linguagem falada; b) para os que falam apresenta prejuízo grande em iniciar o diálogo e mantê-lo; c) estereotipado e repetitivo na linguagem oral (usa frases de propagandas, filmes novelas, programas de televisão) esse exemplo se aplica ao que o indivíduo mais se identifica; d) em crianças a não imitação de alguém próximo (Exemplo: representar o papai, a mamãe, a professora).

- Comportamento repetitivo e estereotipado: a) inquietude intensa com um ou mais padrões estereotipados; b) inflexibilidade em rotinas ou rituais; c) movimento motores específico com as mãos; d) desassossego insistente com partes de um determinado objeto, e não pelo todo.

Grande parte das pessoas autistas tem Distúrbio de Integração Sensorial (DIS): seus sentidos podem ser hipo ou hiperdesenvolvidos. Podem ser capazes de ouvir sons quase inaudíveis, como um alfinete caindo ao chão ou a água correndo nos encanamentos, ou ter sensibilidade a ruídos altos, como liquidificadores e furadeiras; sentir cheiros imperceptíveis para as demais pessoas; podem não suportam luzes fluorescentes, por perceber a luz oscilando como um estroboscópio devido à corrente alternada; toques e outros contatos lhes podem ser desagradáveis; texturas de tecidos e alimentos podem ser desagradáveis (Maciel, 2009, p3).

Para além das principais manifestações de dificuldades como atraso na linguagem oral, fala na percepção sensorial e comportamentos estereotipados, outras questões de saúde podem denotar como hiperatividade, dislexia, transtorno obsessivo compulsivo, déficit de atenção, ansiedade e depressão (Russo, 2017). O autismo sendo particularizado pelas variações de suas características, normalmente antes dos três anos de idade, embora a maioria das pesquisas apontem para a causa do autismo ser uma questão genética como principal fatos para seu desenvolvimento (Mello et al., 2007), ainda não há um consenso sobre isso na comunidade medica.

\subsection{O Autista e o Direito a Arquitetura Inclusiva}

Após a explanação sobre arquitetura inclusiva, é possível situar as discussões sobre inclusão na perspectiva das necessidades de projetos que garantam direitos, neste caso, de crianças com Transtorno do Espectro Autista (TEA) frequentar os espaços comuns regulares fundamentais, notoriamente para sua integração social. Todavia, estruturas físicas de diversas naturezas e diversos usos, como escolas, instituições, parques áreas terapêuticas tradicionais dificultam a inclusão das crianças do espectro (Russo, 2017). Entendendo que:

O meio-ambiente constitui-se sendo o elemento essencial para a estruturação mental da relação espaço-tempo, já que a cognição da realidade se dá a partir de noções espaço-temporais, 'o tempo está implícito em todos os lugares, nas ideias de movimento, esforço, liberdade, objetivo e acessibilidade’. As distâncias, o espaço, os percursos, o "perto” e o "longe" passam a ser compreendidos pelo esforço e não podem ser medidos a partir de referenciais de pessoas que não apresentam nenhuma dificuldade em seus deslocamentos (Tuan, 1983, p. 96).

Em consideração a aspectos indicados entende-se que estímulos sensoriais afetam o comportamento da criança com autismo, (Mostafa, 2008). Sendo aceitável apontar não somente as necessidades concernentes a problemas em relação ao acesso dessas crianças a espaços destinados a terapias, mas também ao conforto de estar inserido de maneira inclusa em ambientes a favorecer até mesmo ao conforto acústico (podem ocasionar eco), barulhos externos e internos. Incentivos 
sensoriais em lugares frequentados por crianças com TEA também podem ser realçados positivamente, conforme Mostafa (2008), a interação sensorial possibilita a organização de ideias e informações, promovendo a habilidade de relacionar estímulos diferentes.

Compreender as relações entre pessoas e ambientes, perpassa a interação social e possibilita a organização de ideias e informações elencadas para o desenvolvimento dessas crianças, promovendo estímulos positivos. Segundo Grandin (2014) nove entre dez pessoas com autismo apresentam um ou mais transtornos sensoriais que interferem na sua capacidade de gostar e sentir prazer em um mundo difícil de ser codificado, e destaca:

Os pesquisadores simplesmente não entendem a urgência do problema. Eles não conseguem imaginar um mundo onde roupas que pinicam o fazem sentir-se pegando fogo, ou onde uma sirene soa como se alguém estivesse perfurando meu crânio com uma furadeira... como socializar pessoas que não toleram o ambiente onde devem se mostrar sociáveis? (Grandin, 2014, p. 80).

As crianças com TEA estão positivamente perceptivas a sua volta, informações, sensações e pessoas, tudo ao mesmo tempo, absorvem e reagem de maneira própria ao perceberem o mundo, também precisam de tempos reclusas (Maciel, 2009). Portanto, a partir dessa ótica, entender o direito a inclusão não está restringido somente a normas técnicas, mas sim em compreender o universo da criança com TEA e todas as variáveis de sua condição. Apesar da temática ser um assunto hodierno, os estudos existentes salientam apenas, em sua maioria, a origem do transtorno e os caminhos a serem usados para o ensino e o tratamento de crianças com TEA. Entretanto, não se encontra uma quantidade relevante de pesquisas dedicadas a discutir como os ambientes e seus aspectos arquitetônicos podem influenciar a vida de adultos e crianças em busca de inclusão, em escolas, ruas, espaços públicos, casas e trabalho (Ama, 2017). Nesta perspectiva, Pallasmaa (2011) afirma:

Nossos corpos e movimentos estão em constante interação com o ambiente; o mundo e a individualidade humana se redefinem um ao outro constantemente. A percepção do corpo e a imagem do mundo se tornam uma experiência existencial contínua; não há corpo separado de seu domicílio no espaço, não há espaço desvinculado da imagem inconsciente de nossa identidade pessoal perceptiva (Pallasmaa, 2011, p. 38).

Partindo da reflexão de Pallasmaa, entende-se a harmonia entre o autista e o espaço ocupado por ele, pois a princípio o que pode ser encontrado são crianças precisando se adaptar aos projetos de escolas, casas e instituições brasileiras (Antunes, 2007).

\subsection{A Equoterapia}

Uma das alternativas terapêuticas para crianças com TEA é a equoterapia, também denominada de Terapia Assistida por Animais (TAA), sendo considerada a equoterapia como uma das modalidades da TAA. Essa modalidade vem ganhando espaço no Brasil nos últimos anos, em decorrência de resultados satisfatórios para quem pratica. Segundo a Associação Nacional de Equoterapia (ANDE) instituição civil, de caráter filantrópico, terapêutico, educacional, cultural, desportivo e assistencial, sem fins lucrativos, o termo equoterapia, refere-se a um tipo de terapia abrangente a todas as atividades e técnicas utilizadoras de cavalo como mediador com finalidades terapêuticas para o indivíduo que apresenta algum tipo de necessidade, seja física ou psiquiátrica (Ande-Brasil, 2016).

A etimologia do termo é composta do latim equus: equídeos, grupos de animais mamíferos, como o cavalo, do termo em grego therapeia: terapia. Ainda segundo a Associação Nacional de Equoterapia (2016) a equoterapia, é uma prática reconhecida por lei, que faz uso do cavalo e suas competências por ser um animal inteligente, domesticável e com porte adequado para terapia, empregando técnicas de equitação, por finalidade a reabilitação e o estímulo da motricidade de pessoas com necessidades e indicações terapêuticas (Amorim, 2020). 
Apesar, de a terapia com cavalos não ser uma descoberta recente para a medicina (Medeiros, 2002), o uso deste tratamento para reabilitação de crianças com TEA, é considerado hodierno para essa função. No Brasil a concepção sobre equoterapia surgiu na década de 70, porém, somente em 1989 a ANDE- Brasil foi criada. Nos últimos anos a terapia assistida por animais obteve aceitação cada vez mais crescente na sociedade, referente ao tratamento de pessoas com TEA.

Não obstante enfoque no estímulo ao desenvolvimento dos campos cognitivos, sociais e também emocional dos pacientes. Segundo a revista Fisioterapia Brasil, descrito por Machado (2019) o fato de os autistas assevera uma conexão especial pelos animais. Desse modo, os pacientes autistas realizam a equoterapia são estimulados a criarem vínculos, mostra-se uma capacidade muito complexa para crianças com TEA,

Assim, a equoterapia vai auxiliar na integração em grupo, no comportamento e na efetividade, no que se refere ao tratamento de crianças autistas, promovendo inúmeros efeitos benéficos, através do trabalho em torno do estímulo corporal, uma vez que, embora o paciente não execute movimentos, estará recebendo os estímulos corporais por meio do movimento tridimensional proporcionado pelo passo do cavalo (Machado, 2019, p.685).

A relevância da equoterapia em diversos estudos realizados até o momento, revela o emprego dessa terapia no favorecimento da socialização, do desenvolvimento global e até mesmo na alfabetização de crianças com TEA (Ande-Brasil, 2016). Ratificando ainda, mesmo a equoterapia tendo reconhecimento de Lei 1.830\19, ainda não é um tratamento acessível e conseguintemente não pode ser considerada uma terapia inclusiva, concernente a informação sobre a equoterapia e seus proventos a saúde do público carente de TAA, para maior apoio da comunidade e de políticas públicas eficientes ao engajamento dessa terapia. Pois a equoterapia promove melhorias no desenvolvimento motor, psicomotricidade, processo de aprendizagem, autoestima, atenção, disciplina, concentração e também a memória, resume-se a qualidade de vida de cada indivíduo, (Fiuza, 2017).

\section{Discussão}

\subsection{Centros de equoterapia em Vitória da Conquista-BA}

Os Centros de Equoterapia são construídos não somente para suprir demandas construtivas legais, mas também, para inferir na qualidade do acesso de crianças ao ambiente de terapia e ainda, promover sensorialmente a interação humano-animal fundamental em TAA (Ande-Brasil, 2016). Para amparar as pesquisas realizadas, foram feitos dois estudos de caso, no município de Vitoria da Conquista, o primeiro no Centro Conquista de Equoterapia, localizado na área urbana e o Centro de Equoterapia e Instituto Lar dos Kerubins, localizado na zona rural.

O Centro Conquista de Equoterapia está localizada na zona urbana de Vitória da Conquista, no estado da Bahia, na rua Siqueira Campos, bairro Candeias, no espaço chamado de Parque de Exposições. O parque de Exposições é uma área de um terreno integrado a área de eventos sociais e agropecuários. Filiado a ANDE-Brasil (Associação Nacional de Equoterapia) e chancelado pela ABAE (Associação Baiana de Equoterapia) atendendo a 45 pacientes (crianças, jovens e adultos). O centro é composto por salas de atendimento clínico, banheiros adaptados, despensa, pátio coberto e pátio aberto, conforme (Figura 1). 
Figura 1. Espaço dentro do Parque de exposições destinado ao Centro Conquista de Equoterapia.

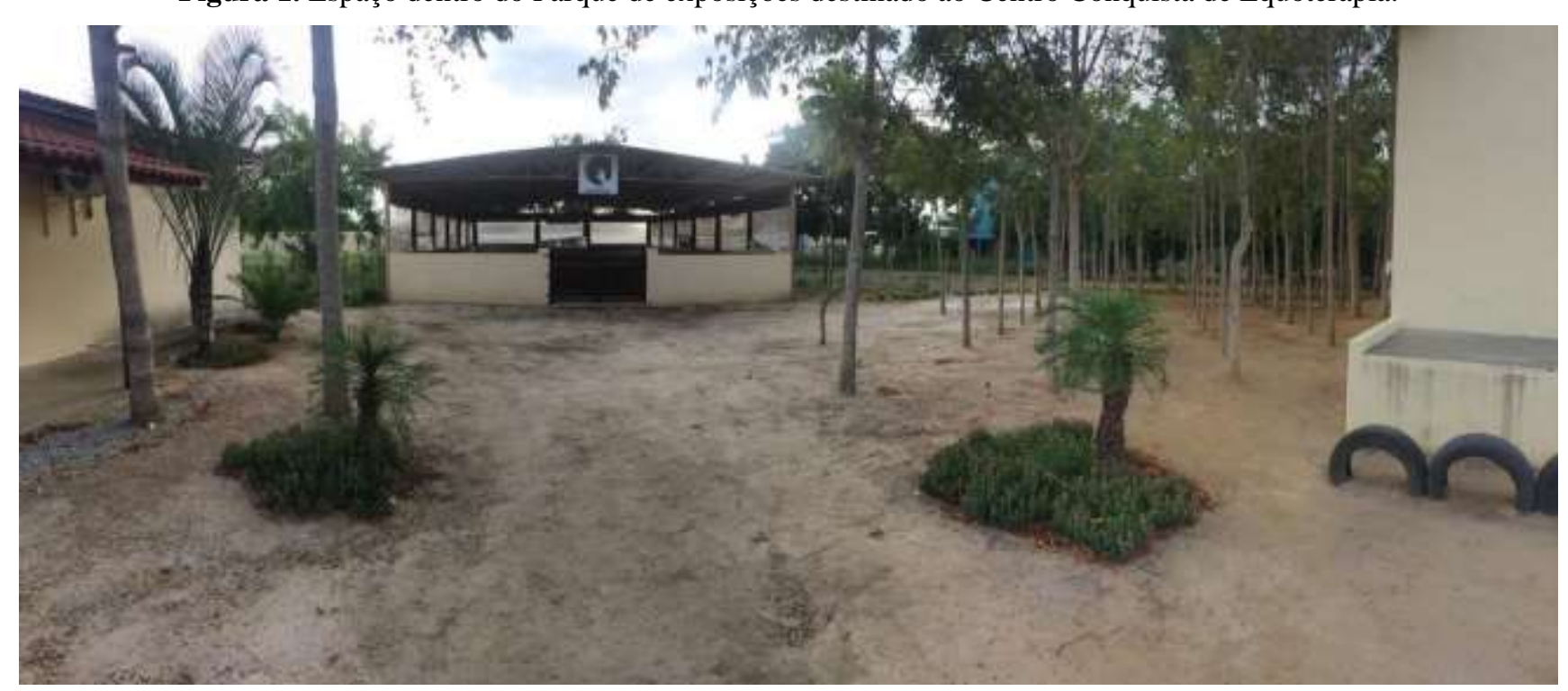

Fonte: Conquista Equoterapia (2017).

O Conquista Equoterapia fica em uma região central do município em um espaço adaptado dentro do Parque de Exposições da cidade, essa área também é atribuída a eventos sociais, leilões agropecuários e shows, revelando um desafio no cotidiano de crianças com TEA. Para Grandin (2014) a maioria dos pesquisadores não conseguem imaginar uma vida em que cada situação nova, ameaçadora ou não, vem como uma descarga de adrenalina.

Segundo Grandin (2014), quebras de rotina, inconstância e incômodos acústicos, são processos dolorosos para um autista, perante isto, o Centro Conquista de Equoterapia mostra uma fragilidade em manter uma prática consistente para crianças com TEA, sendo o espaço destinado para TAA não exclusivo, pois recebe eventos com demandas próprias, ocasionando interrupções momentâneas na terapia. Esses eventos podem restringir o acesso ao tratamento com equoterapia, por terem duração estendida e requererem pequenas reformas. Questionando assim como socializar pessoas que não toleram o ambiente onde devem se mostrar sociáveis e como compreender que este ambiente pode ser encarado como lugar de terapia (Rubim, Al, Da Hora, Aflt \& Lobato, Al, 2020), devido as inconsistências em subprogramas não relacionadas ao Centro, mas sim ao uso do espaço compartilhado pelo Instituto com toda a programação secular da cidade. A Figura 2 mostra o local em dias de eventos não direcionado a terapia, vale destacar que para realização de algum evento extra terapêutico, o local precisa se adequar antecipadamente envolvendo uso de maquinário que produz ruídos e a inacessibilidade do espaço para equoterapia neste período de tempo. 
Figura 2. Área em dia de evento.



Fonte: Portal dos Municípios (2018).

O segundo centro existente é o Centro de Equoterapia e Instituto Lar dos Kerubins (CEILK), localizado na zona rural de Vitória da Conquista, no estado da Bahia, na Rodovia Conquista-Itambé, BA 263, Chácaras Capinal, em um terreno reservado somente para as atividades equestres. Filiado a ANDE-Brasil (Associação Nacional de Equoterapia), o espaço conta com pátio aberto, área verde, sala de atendimento multifuncional, diretoria, despensa e banheiro convencional. A (Figura 3) mostra a área de atendimento que também funciona como residência para a proprietária do Instituto. 
Figura 3. Centro de Equoterapia e Instituto Lar dos Kerubins.

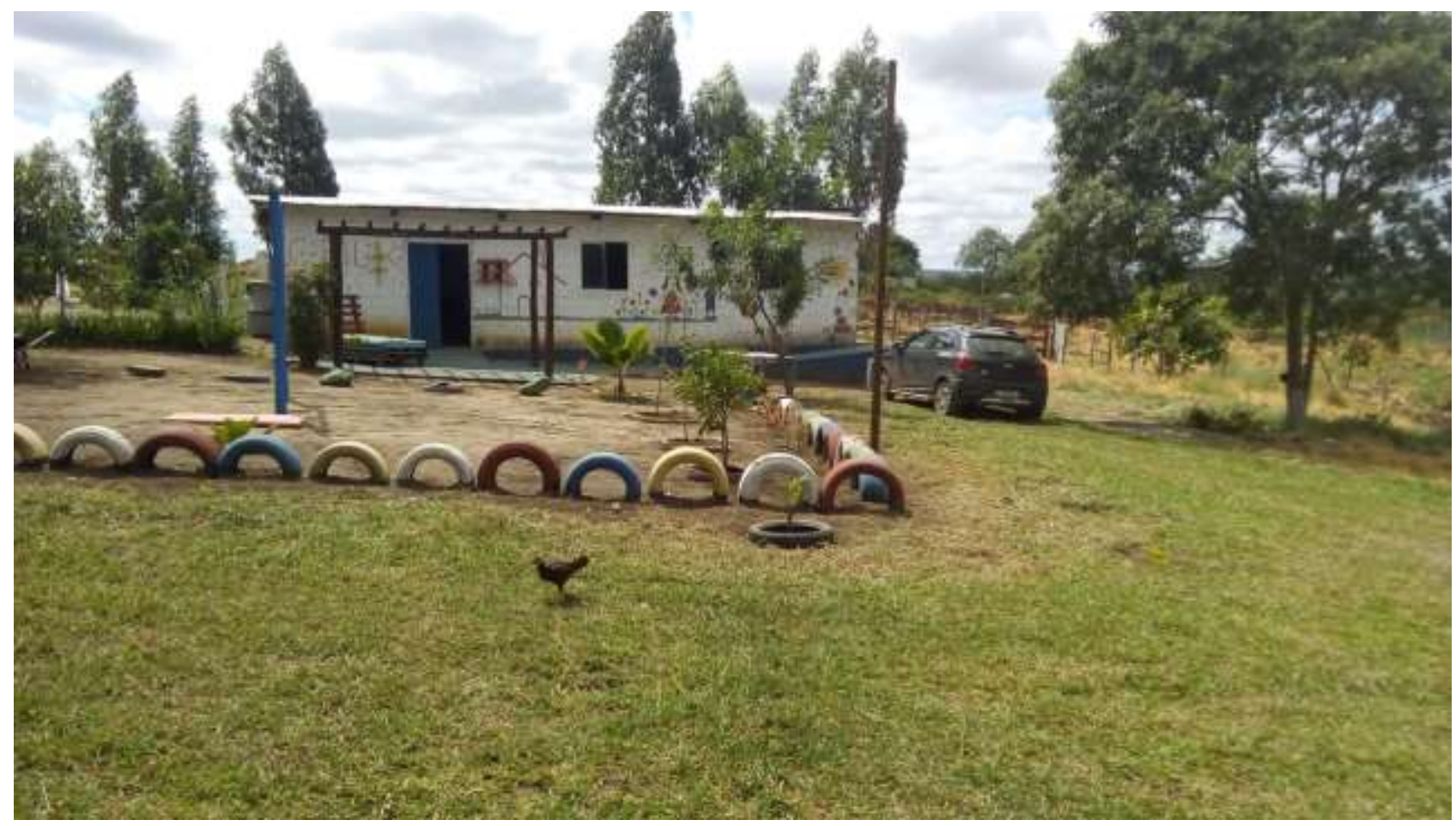

Fonte: Acervo pessoal.

Apesar de ser um local de atendimento exclusivo ao tratamento equoterápico, o Centro Lar dos Kerubins apresenta desafios. $\mathrm{O}$ acesso limitado, sendo um fator decisivo para que crianças consigam ingressar com facilidade no Instituto, as ruas não possuem calçamento e também falta sinalização adequada, possível observar na (Figura 4). A acessibilidade segundo a NBR 9050 é a possibilidade e condição de alcance que todos devem desfrutar. A dificuldade do acesso ao CEILK, se mostra também na distância do centro urbano do município (Figura 5), ocasionando custo para o deslocamento com transporte próprio de cada usuário do Instituto. Vale ressaltar que apesar da distância se mostrar relevante para locomoção de crianças, o ambiente rural contribui para o bem estar dos animais (Cirillo, 2001), agentes importantes no tratamento, e também a falta de ruídos provocados por movimentações urbanas de diversas naturezas (Grandin, 2014), agrega a vivencia de crianças autistas.

Figura 4. Estrada de acesso ao Instituto.

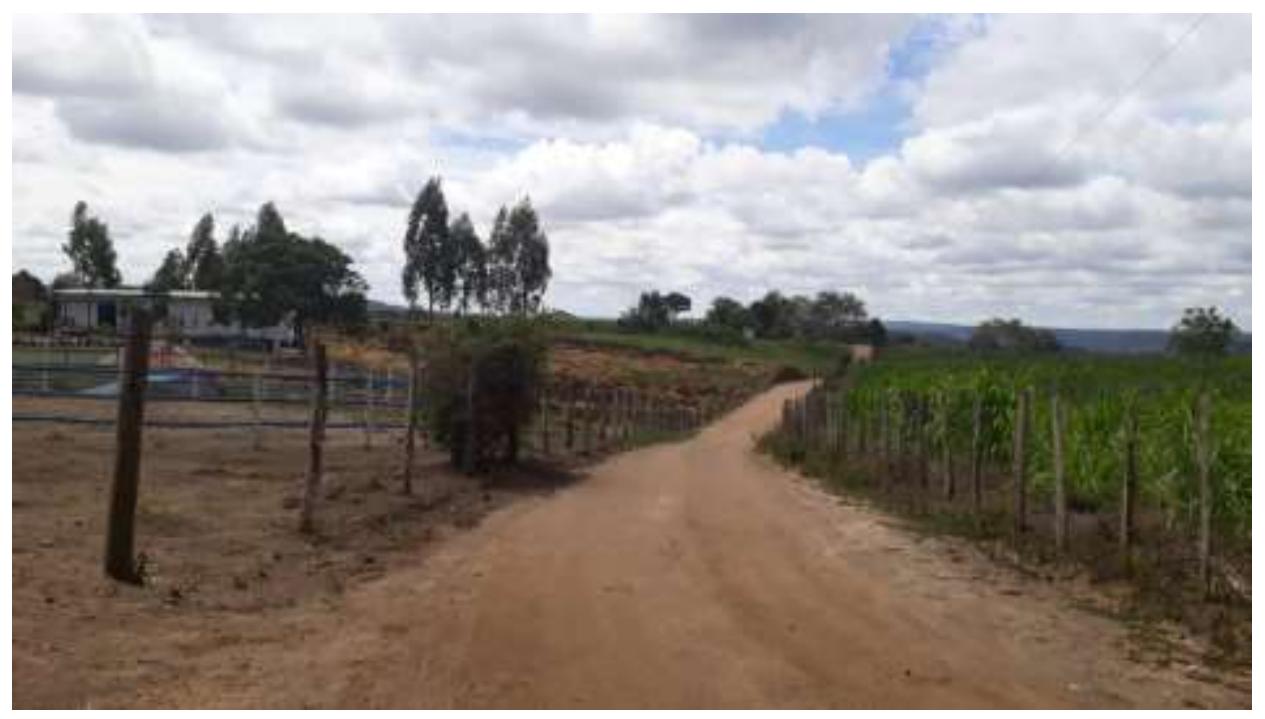

Fonte: Acervo pessoal. 
Figura 5. Mapa de Vitória da Conquista e indicação da localização do Instituto.

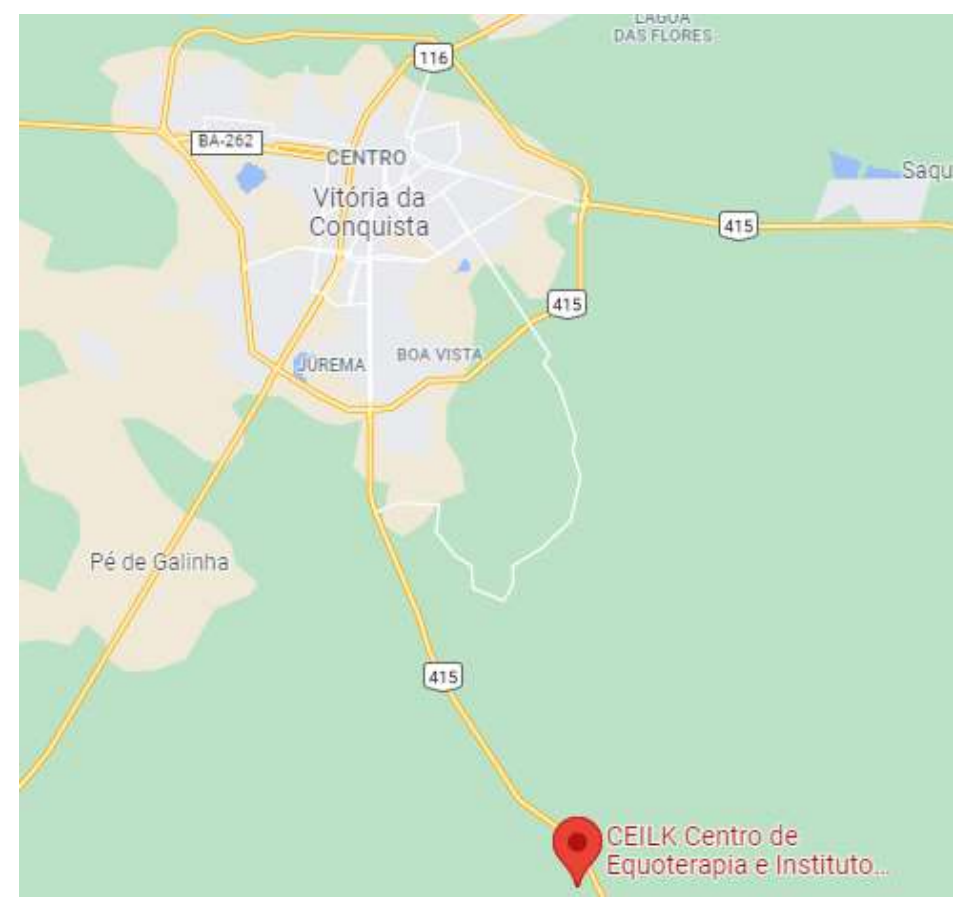

Fonte: Google Earth. Editado pela autora. (Acesso em 01 de out. de 2021).

A distância entre o centro urbano de Vitória da Conquista e o CEILK é 17,5 quilômetros, essa distância pode inviabilizar que crianças de comunidades carentes da região possa usufruir da terapia neste instituto, a (Figura 5) ilustra espacialmente essa distância.

\subsection{Referência de arquitetura inclusivo para TAA.}

A arquitetura inclusiva para TAA, que seja acessível as crianças autistas contemplando espaços adequados aos animais sendo um canal facilitador para o tratamento com cavalos, mostra-se como esteio para a concepção de espaços dentro destes parâmetros (Uzun, 2005). Para referenciar o esperado para um centro especializado em equoterapia, o Centro Capixaba de Equoterapia - Espírito Santo, disponibiliza tratamento de Equoterapia, Terapia Ocupacional, Integração Sensorial e Fisioterapia, o local possui recepção, sala de atendimento, sala de fisioterapia, sala de interação e estímulos como é possível ver em (Figura 6), local de espera dos pais, escritório, dois banheiros para funcionários, fraldário, dois banheiros para pacientes sendo que um é adaptado para portadores de necessidades especiais. 
Figura 6. Sala adaptada multifuncional.

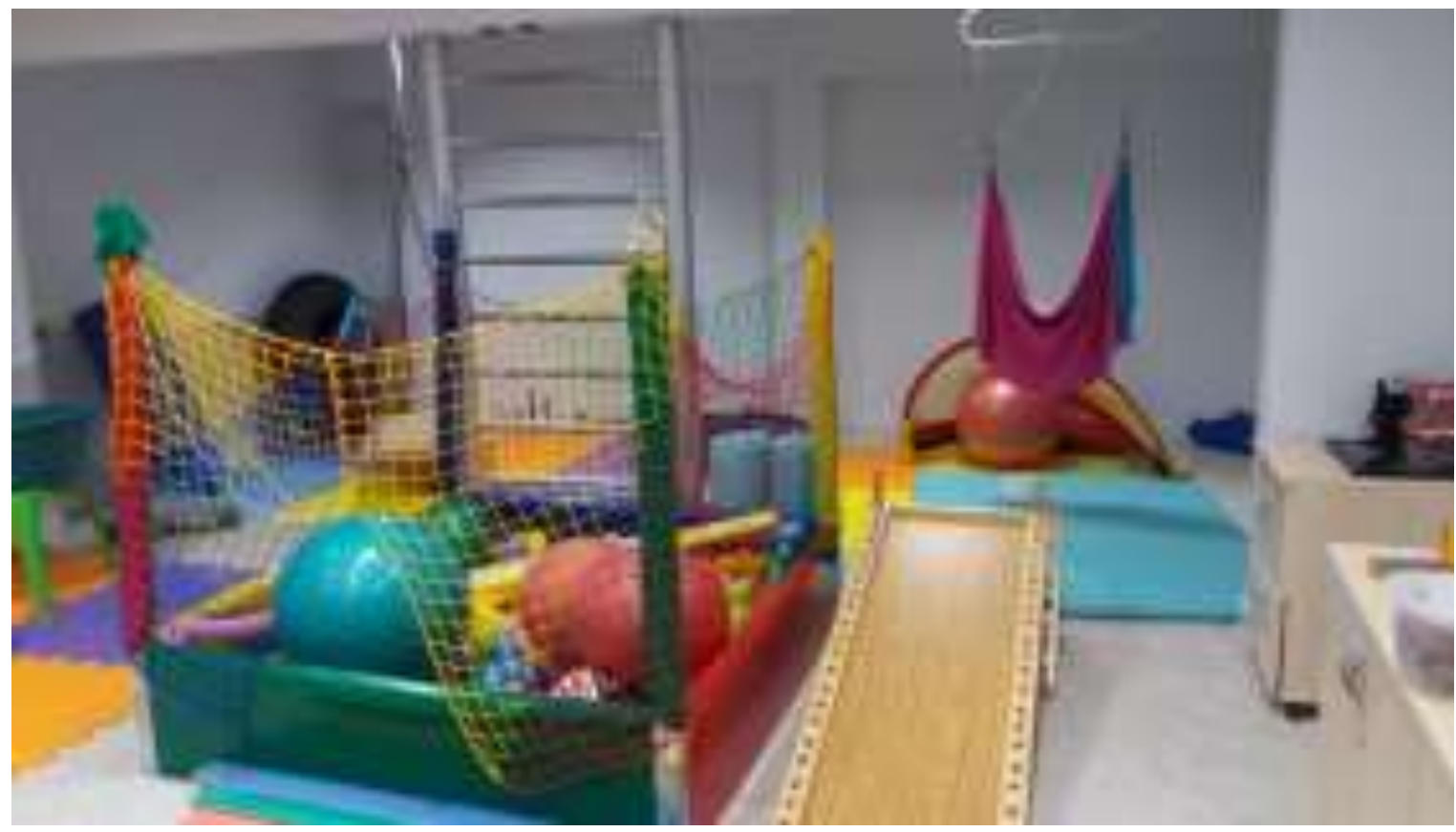

Fonte: Adriely Giacomin Schiavon (2017).

Positivamente são avaliados no Centro salas com função de apoiar a equoterapia, como a sala de interação e estímulos é bem estruturada e possibilita estímulos que variados para crianças com TEA, acesso com rampas seguindo as recomendações da NBR 9050 e acusticamente adequado, o acesso também pode ser visto como referência para centros de equoterapia em Vitoria da Conquista pois favorece o conforto sonoro e sensorial. As vias de entorno garantem acessibilidade ao local e a faixa de vegetação permite conforto aos usuários e aos animais podendo ser visto através da (Figura 7).

Figura 7. Localização espacial do Centro Capixaba de Equoterapia - Espirito Santo.

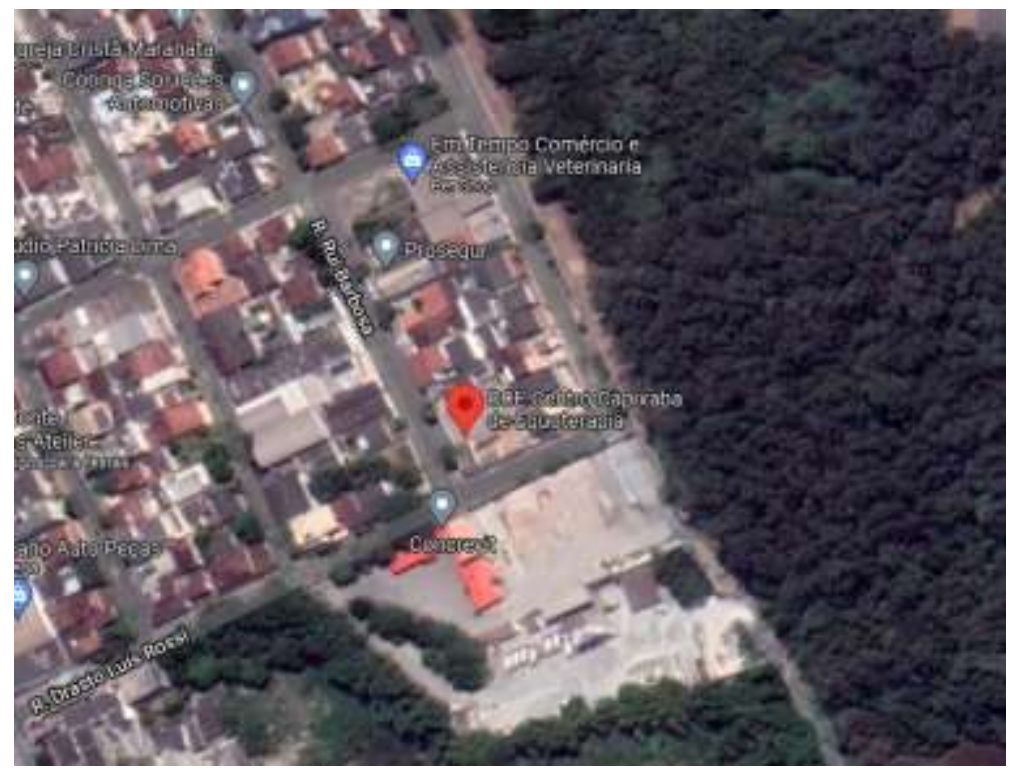

Fonte: Google Earth. Editado pelo autor. (Acesso em 05 de out. de 2021). 
Figura 8. Picadeiro protegido e com drenagem.

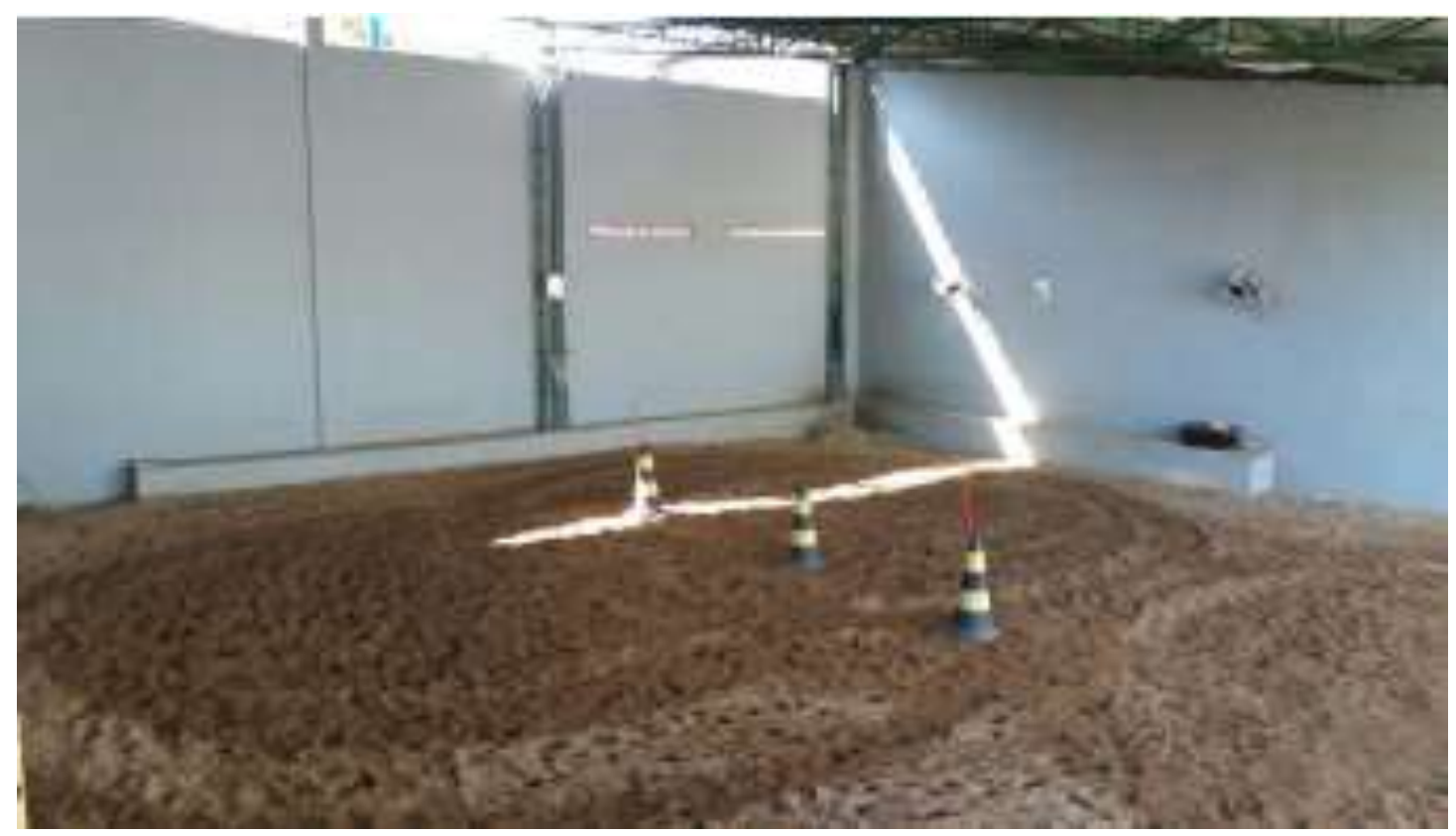

Fonte: Adriely Giacomin Schiavon (2017).

Outro ponto são as baias dispor do método de filtro para diminuir o mal cheio da urina, utilizando assim o piso de areia que não danifica os cascos dos animais e fornece um local confortável, o picadeiro possui o mesmo método disposto nas baias (Figura 8), além de contar com paredes servindo de barreira física para sons e intemperes climáticos, esses recursos arquitetônicos proporcionam vínculos de inclusão e autonomia, segundo Pallasmaa (2011) o ambiente interage diretamente na rotina dos que usam. Adaptações na arquitetura que garantem autonomia a crianças que precisam de terapias, podem ser encaradas como necessidades básicas de acolhimento e acessibilidade (Martins et al, 2017).

\section{Conclusão}

O desenvolvimento do tema discutido neste artigo se mostra válido para a sociedade acadêmica, tendo em vista os âmbitos físicos que fazem parte do processo de inclusão dentro da TAA para crianças com transtorno do espectro autista. A legislação ampara direitos oportunizando a inserção em lugares não exclusivamente destinado ao tratamento, mas também em qualquer círculo, grupo ou esfera em que uma pessoa com deficiência permanente ou momentânea precisa estar, bem como a acessibilidade. Entretanto, pode ser observado a partir das vivências e dos estudos demonstrados neste trabalho, efetivamente sob o ponto de vista da arquitetura a necessidade de adaptações nas edificações agregando, portanto, seu engajamento como ferramenta para garantir melhorias para serem realmente materializados no cotidiano de todos.

Nesse momento, o potencial dos centros de equoterapia no município pode ser ressaltado pelo trabalho e os benefícios alcançados durante anos de tratamento à crianças autistas, contudo, faz-se indispensável manter o olhar sempre em desenvolvimento para auxiliar de diferentes formas todos usuários dos institutos, com melhorias nos acessos, garantindo uma rotina segura, através de equipamentos e soluções arquitetônicas para assegurar as criança integração e constância, priorizando aspectos construtivos para melhorar as condições de uso, tais como: barreiras sonoras, rampas de acesso, setorização adequada dos espaços, filtro para diminuir odores típicos desses centros em baias e em áreas de equitação, passagens restritas para não serem interrompidos por outros eventos, questões de urbanismo como sinalização correta em vias e regularização das mesmas e piso tátil em calçadas e em áreas internas. Essas adequações sugeridas indicam benefícios básicos para a independência e a 
socialização correta de crianças com autismo, dentro dessa perspectiva, é possível destacar quando se reflete sobre autonomia, também se discute a relevância da consciência de inclusão nas ações dentro do papel do arquiteto em projetar.

As informações extraídas deste trabalho são válidas para a discussão atual, a necessidade de mais estudos relacionando a arquitetura com os desafios do autismo. Conclui-se que para pesquisas que norteiam projetos de arquitetura, o cuidado com a elaboração de áreas de centros de equoterapia perpassa por caminhos de integração e acessibilidade, pois, estes espaços devem ser projetado para ser utilizado de maneira plena e sem transtorno a mobilidade e as demais características de cada indivíduo, então a arquitetura inclusiva se mostra como caminho possível para assegurar aos autistas a melhor forma de auxilio no enfrentamento dos obstáculos vivenciados como também garantir acolhimento integral em centros equoterápico.

\section{Referências}

Amorim, L. C. D, (2020). Autismo: Tratamento. In: Associação De Amigos Do Autista (Ama). Website Ama. https://www.ama.org.br/site/autism o/tratame nto/.

Antunes, K. C. V., (2007). Uma leitura sociológica da construção do espaço escolar à luz do paradigma da educação inclusiva. Dissertação (Mestrado). Universidade Estadual do Rio de Janeiro na área de Educação.

Bechara, E, (2009). Moderna gramática portuguesa. Nova Fronteira.

Brasil, Ande, (2016). Apostila da Associação Nacional de Equoterapia, 2016. Website Ande-Brasil. http://equoterapia.org.br/.

Brasil, Secretaria Geral, (2019). Presidência da República Secretaria-Geral Subchefia para Assuntos Jurídicos. Website. http://www.planalto.gov.br/ccivil_03/_ato2019-2022/2019/lei/L13830.

Brasil. Estatuto da pessoa com deficiência, (2015). Lei brasileira de inclusão da pessoa com deficiência: Lei $\mathrm{n}^{\circ} 13.146$.

Cirillo, L. de. C. ANDE - BRASIL, (2001). Apostila de Equoterapia. Brasília.

Deleuze, G, (2009). Diferença e repetição. (2a ed.), Graal.

Eckert, D, (2013) Equoterapia como recurso terapêutico: análise eletromiográfica dos músculos reto do abdômen e paravertebral durante a montaria. Dissertação (Mestrado). Centro Universitário Univates, Lajeado.

Fiuza, J. \& Peranzoni, V. C, (2017). Equoterapia Como Recurso Pedagógico: Dificuldades de Aprendizagem. Website Owa. https://blog.owa.com.br/5-coisasque-voce-precisa-saber-sobre-arquitetura-inclusiva.

Gil, A. C, (2010). Como elaborar projetos de pesquisa. Atlas.

Grandin, T, (2014). O cérebro autista: Pensando através do espectro. Record.

IBGE - Instituto Brasileiro De Geografia E Estatística, (2012). “Censo Demográfico 2000/2010”. Website Portal do governo brasileiro. https://cidades.ibge.gov.br/brasil/ba/vitoria-da-conquista/panorama.

Lakatos, E. M \& Marconi, M. A, (2003). Fundamentos de metodologia científica. (5a ed.). Atlas.

Machado, T. L, (2019). Dançaterapia no Autismo: um estudo de caso. Revista Fisioterapia e Pesquisa.

Maciel, M. M \& Filho, A. P. G., (2009). Autismo: uma abordagem tamanho família.

Martins, M. S, Et Al, (2017). Arquitetura inclusiva: Centro de habilitação e reabilitação para deficientes visuais. Santa Catarina.

Mederios, M, (2002). Equoterapia Bases E Fundamentos. Revinter.

Mello, A. M.; Ho, H; Dias, I \& Andrade, M, (2007). Retratos do Autismo no Brasil. AMA.

Mostafa, M, (2008). An Architecture for Autism: Concepts of Design Intervention for the Autistic User. Archnet-IJAR, International Journal of Architectural Research.

Oliveira, L. A, (2007). Coisas que todo professor de português precisa saber: A teoria na prática. Parábola Editorial.

Oliveira, M, (2007). Como fazer pesquisa qualitativa.

Pallasmaa, J, (2011). Os olhos da pele: A arquitetura e os sentidos. Bookman.

Ribeiro, D. S, (2014). Equoterapia: Uma Intervenção No Município De Vitória Da Conquista- Ba. Vitoria da Conquista.

Rodrigues, G. V. E Vergana, L. G. L, (2019). As contribuições para a Arquitetura no contexto da Educação Especial para a inclusão de crianças com autismo. Santa Catarina. 
Research, Society and Development, v. 10, n. 14, e76101421793, 2021

(CC BY 4.0) | ISSN 2525-3409 | DOI: http://dx.doi.org/10.33448/rsd-v10i14.21793

Rubim, A. L.; Da Hora; A. F. L. T., \& Lobato, A. L. (2020). Contribuições da avaliação neuropsicológica no diagnóstico do autismo. Open Access Journal of Neurology and Neurosurgery, 13 (2): 555857. 10.19080.

Russo, F, (2027). Graus de autismo - importante saber. Website Neuro Conecta. https://neuroconecta.com.br/graus-de-autismo-importante-saber/.

Silveira, M. M. \& Wibelinger, L. M, (2011). Reeducação da Postura com Equoterapia. Revista neurociência.

Tuan, Y, (1983). Espaço e Lugar: A Perspectiva de Experiência. Difel.

Uzun, A. L. de L, (2005). Equoterapia: aplicação em distúrbios do equilíbrio. Vetor.

Vergana, L. G. L, et al, (2011). Acessibilidade entre mundos: Uma arquitetura mais inclusiva aos autistas. 